\title{
Mixture design approach to evaluate fresh properties of SCC made with various sands
}

\author{
Bouziani T ${ }^{1,}$, Bédérina $\mathrm{M}^{1}$, Makhloufi $\mathrm{Z}^{1}$ and Hadjoudja $\mathrm{M}^{2}$
}

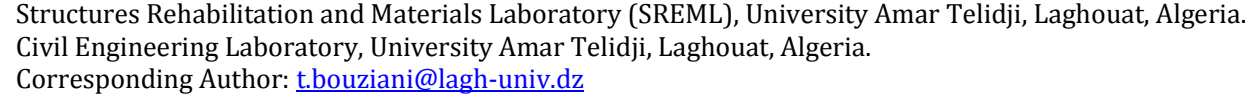

\begin{abstract}
The aim of the present paper is to provide a mixture design modelling to evaluate the effect of different sand types on fresh properties of self-compacting concrete (SCC). A statistical approach was used to highlight the effect of river sand (RS), crushed sand (CS) and dune sand (DS) as proportions in binary and ternary systems in SCC composition. The responses of the derived statistical models are sand packing density (SPD), T500 and J-ring. The resulting mathematical models are used to illustrate the variation of different responses in ternary contours plots with respect to the proportions of RS, CS and DS. This offers flexibility to optimize RS, CS and DS blends with tailor-made of a given property that suit a particular recommendations. Results indicate that SPD of RS can be enhanced by a $40 \%$ of CS and $30 \%$ of DS proportions. Moreover, it is shown that flowability, measured by J-ring, can be improved by the increase of CS and DS in RS-CS and RS-DS binary systems. Results also indicate that passing ability measured with T500 decreased with the increase of CS proportion and increased with the increase of DS proportion in binary and ternary systems.
\end{abstract}

Key words: Self-compacting concrete, fresh properties, river sand, dune sand, crushed sand, mixture design modeling.

\section{Introduction}

The main distinguishing of self-compacting concrete (SCC) is to fill the forms and consolidate without the need of vibration (Okamura, 2003). Beside these characteristics, SCC will enable a considerable reduction of the acoustic noise levels and the use of secondary raw materials. Recently, there is an increasing attention on SCC technology in Algeria. The principal reasons for this interest are not only for the technical advantages of SCC, but concern also the severe shortage of coarse aggregates, even though sands of different types and grading (such as dune sand and crushed sand) are available in large quantities (Al-harthy, 2007; Abidelah, 2009). In this regard, the development of new concretes that necessitate less coarse aggregates to be used, such as SCC responds to some of the urgent needs of the construction sector. The limitation of coarse aggregates volume in SCC is also one of the most factors affecting their passing and filling abilities while preventing segregation (Ramge, 2010; Zhu, 2005).

On the other hand, several research works have investigated the use of sand as total or partial substitute of coarse aggregates to develop new concretes, which have mechanical properties comparable with conventional concretes (Zhu, 2005; Bédérina, 2005). Due to the fineness of sand, SCC requires a high water demand and a large cement content to achieve high fluidity. Therefore, the use of superplasticizers and fine powders are thus two of the central aspects of self-compacting concrete mixture proportioning (Albert, 2010; Felekoğlu, 2008b; Girish, 2010). Sand from natural deposits or crushed rocks is a suitable material used as a fine aggregate in concrete production (Al-harthy, 2007). Bédérina et al. (2005) reported that dune sand is a useful component in optimizing particle size distribution of river sand and thereby improving workability and compressive strength of sand-concrete mixtures. Kay et al. (1994) also investigated the potential of using dune sand as fine aggregates in concrete. Results indicated that dune sand may provide a readily available alternative material for use as fine aggregate in concrete. Crushed sand, produced from crushing rocks units, can has a large potential of applications in various fields of civil engineering (Abidelah, 2009). The employment of crushed 
sand may be a second alternative source of filler and thereby can improve the cost effectiveness of SCC, by reducing the demand for external filler addition (Felekoğlu, 2008a).

Nowadays, some research results about the effect of sand type on the properties of flowable mixtures have been established, however, the related researches are focused on flowing sandconcretes and self-compacting mortars (Bouziani, 2012; Benabed, 2012). Therefore, the effects of sand type and content on fresh and mechanical properties of SCC needs more investigate.

In this study, some fresh properties of SCC made with different sand types have been investigated. These properties were introduced in this paper, in complementary of our recent investigation on the effect of sand type on fresh and hardened properties of SCC (Bouziani, 2013). A mixture design approach was used to highlight the effect of three types of sands proportions, river sand (RS), crushed sand (CS) and dune sand (DS) on these properties.

\section{Mixture design approach}

Statistical modelling approaches are commonly used to identify the relative significance of primary mixture parameters and their coupled effects on relevant properties of SCC (Khayat, 1999; Yahia, 2001; Bayramov, 2004; Sonebi, 2005; Bouziani, 2012b; Bouziani, 2013). For the present work, experiments were designed according to a mixture design approach. In contrast to classical non-mixture designs (factorial and response surface designs), all factors are constituent proportions of a mixture. Since these proportions must always sum to 1 , the last component proportion is dictated by the sum of all the others. In this mixture situation, the factors are not independent, which has consequences on the design process (Goupy, 2007).

A simplex-lattice mixture design was carried out, with three factors and five levels, to evaluate the effect of three types of sands (RS, CS and DS) on the properties of SCC. All other SCC components (coarse aggregate, cement, addition, superplasticizer and water) were kept constant. The simplex-lattice design is a space filling design that creates a triangular grid of combinations, as shown in Fig. 1, where the number of combinations $(C)$ is expressed by the flowing relation:

$$
C=\frac{(q+m-1) !}{m !(q-1) !}
$$

Where, $q$ is the number of factors and $m$ the number of levels.

With three factors and five levels, the number of combinations to be treated is 21 .

Using this approach, a mathematical model describing the effect of three types of sands proportions and their blends on given property can be established.

In this study, a second-degree model was used with three non-independent variables (proportions of RS, CS and DS) and five levels. The model is expressed as follows:

$$
Y=b_{1} \times R S+b_{2} \times C S+b_{3} \times D S+b_{4} \times(R S \cdot C S)+b_{5} \times(R S \cdot D S)+b_{6} \times(C S \cdot D S)
$$

The model's coefficients $\left(b_{i}\right)$ represent the contribution of the associate variables on the response $Y$. These coefficients are determined by a standard least-square fitting. Analyses of variance are used to evaluate the significance of each term in the model. The residuals are used to calculate the variance of the coefficients, which is used to find the standard for testing whether a coefficient is significant or not (Goupy, 2007). 


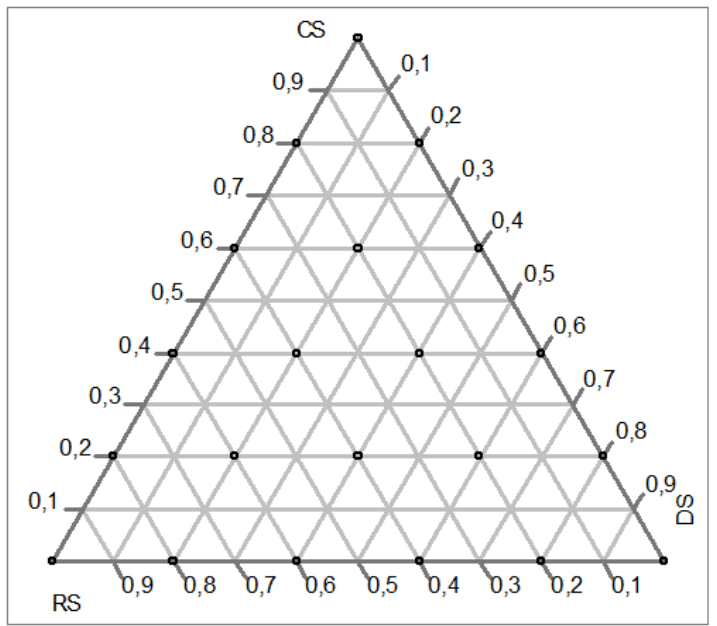

Fig 1. Illustration of the simplex-lattice design with three factors (RS, CS and DS) and five levels.

\section{Experimental program}

\subsection{Materials}

Ordinary Portland Cement CEM I 42.5 and marble powder lime-stone type were used in this study. The chemical and physical properties of cement and marble powder are presented in Table 1. Three types of sand (RS, CS and DS) and crushed limestone-type gravel were used. The particle size gradations obtained thorough sieve analyses method of selected sands and gravel are presented in Fig. 2. The maximum sizes of aggregates are $10 \mathrm{~mm}$ for gravel, $5 \mathrm{~mm}$ for RS, $4 \mathrm{~mm}$ for CS and $1.63 \mathrm{~mm}$ for DS. Physical properties of used aggregates are presented in Table 2. The polycarboxylate-type high range water reducing superplasticizer, Medaflow-30, fabricated by Granitex, was used. The solid content, $\mathrm{pH}$ and specific gravity of the superplasticizer are $30 \%$, 6 and 1.07 respectively.

\subsection{Mixture proportions}

A total of 21 SCC mixtures were prepared for this investigation. In all the mixtures, the amounts of gravel, cement, marble powder, superplasticizer and water were kept constant. The mix proportioning has been designed according to AFGC recommendations (AFGC, 2008). In other words, the gravel/sand ratio was kept equal to 1 and the volume of paste was chosen $360 \mathrm{l} / \mathrm{m}^{3}$ (in the range 330 to $400 \mathrm{l} / \mathrm{m}^{3}$ ).

Table 1: Chemical composition and physical properties of cement and marble powder.

\begin{tabular}{|c|c|c|}
\hline Analysis (\%) & $\begin{array}{c}\text { Portland } \\
\text { cement }\end{array}$ & $\begin{array}{c}\text { Marble } \\
\text { Powder }\end{array}$ \\
\hline \hline $\mathrm{CaO}$ & 65.9 & 55.6 \\
\hline $\mathrm{SiO}_{2}$ & 21.9 & 0.6 \\
\hline $\mathrm{Al}_{2} \mathrm{O}_{3}$ & 4.8 & 0.4 \\
\hline $\mathrm{Fe}_{2} \mathrm{O}_{3}$ & 3.5 & 0.2 \\
\hline $\mathrm{MgO}_{\mathrm{Kg}} \mathrm{O}$ & 1.6 & 0.1 \\
\hline $\mathrm{SO}_{3}$ & 0.5 & - \\
\hline $\mathrm{CaCO}_{3}$ & 0.48 & - \\
\hline $\mathrm{Na}_{2} \mathrm{O}$ & - & 90 \\
\hline $\mathrm{Cl}$ & - & - \\
\hline $\mathrm{LOI}$ & 0.1 & 0.1 \\
\hline Specific density & 1.2 & 43 \\
\hline Blaine Surface $\left(\mathrm{cm}^{2} / \mathrm{g}\right)$ & 2792 & 2.1 \\
\hline
\end{tabular}


Total sands content was $848 \mathrm{~kg} / \mathrm{m}^{3}$, in which 21 combinations from different proportions of three sands (RS, CS and DS) were carried out using the mixture design plan (as presented in Table 3). Gravel content was $880 \mathrm{~kg} / \mathrm{m}^{3}$. Cement and marble powder contents were $380 \mathrm{~kg} / \mathrm{m}^{3}$ and $199 \mathrm{~kg} / \mathrm{m}^{3}$ respectively. Water to binder ratio was 0.4 . The amount of superplasticizer was $1.6 \%$ by weight of cement.

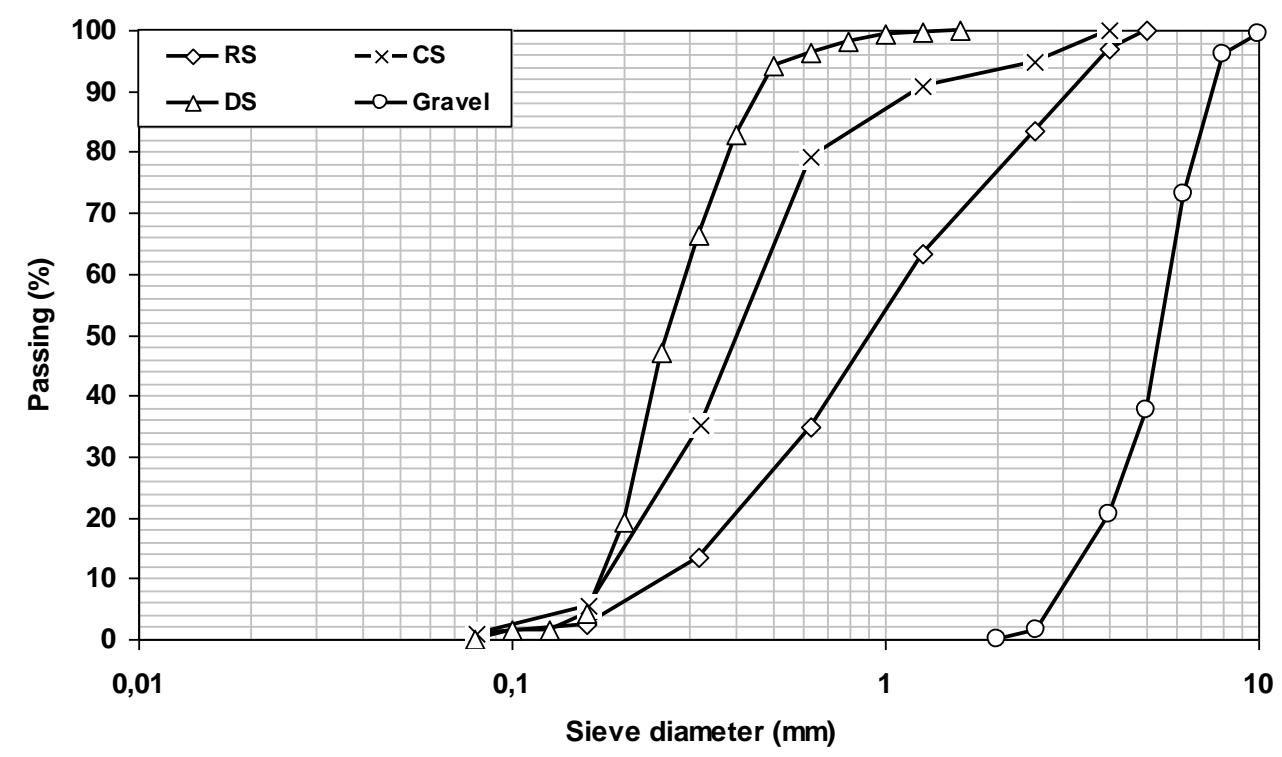

Fig 1: Particle size gradations of RS, CS, DS and gravel.

Table 2: Physical properties of aggregates.

\begin{tabular}{|c|c|c|c|c|}
\hline \multirow{2}{*}{ Property } & \multicolumn{4}{|c|}{ Aggregate } \\
\cline { 2 - 5 } & RS & CS & DS & Gravel \\
\hline \hline Specific density & 2.65 & 2.7 & 2.67 & 2.75 \\
\hline Fineness modulus & 3.03 & 2.14 & 1 & $/$ \\
\hline Sand equivalent & 87.7 & 82.8 & 91 & $/$ \\
\hline Absorption (\%) & 1.79 & 5.71 & 2.04 & 1.83 \\
\hline
\end{tabular}

\subsection{SCC testing procedure}

In mixing, gravel, sands, cement and marble powder were blended first then high-range water reducing superplasticizer and water were added to the mixture. Immediately after mixing, flowability and passing ability were evaluated using the following tests: T500 (s) and J-ring (cm). Packing density (SPD) test was also conducted on dry sands mixtures.

\section{Results and discussion}

\subsection{Statistical models}

The test results of 21 SCC mixtures are used to establish statistical models that can describe the effects of RS, CS and DS proportions as well as all possible interactions in binary and ternary systems, on the variation of each response.

The coefficients of proposed models, as mentioned in relation (2), are evaluated basing on student's distribution, to eliminate non-significant (N-S) terms. In this study, the acceptance probability for the coefficients is set at a $p$-value less than 0.05 . Coefficients of derived models (Coeff.), correlation coefficients $\left(\mathrm{R}^{2}\right)$ and $p$-values for fresh properties responses are shown in Tables 4 . The final models of SPD, T500 and J-ring can be written as: 


$$
\begin{aligned}
& Y_{S P D}=1.5 \times R S+1.5 \times C S+1.6 \times D S+0.33 \times(R S \cdot D S)+0.37 \times(R S \cdot C S)+0.4 \times(C S \cdot D S) \\
& Y_{T 500}=4.7 \times R S+3.9 \times C S+19.2 \times D S-25 \times(R S \cdot D S) \\
& Y_{J-\text { ring }}=72.5 \times R S+64.4 \times C S+43 \times D S+48.5 \times(R S \cdot D S)
\end{aligned}
$$

\begin{tabular}{|c|c|c|c|}
\hline \multirow{2}{*}{ Mix. $N^{\circ}$} & \multicolumn{3}{|c|}{ Sands combinations } \\
\hline & RS & $\mathrm{CS}$ & DS \\
\hline 1 & 0.8 & 0 & 0.2 \\
\hline 2 & 0 & 0.8 & 0.2 \\
\hline 3 & 0.2 & 0.6 & 0.2 \\
\hline 4 & 0.4 & 0.4 & 0.2 \\
\hline 5 & 0 & 0 & 1 \\
\hline 6 & 0.2 & 0 & 0.8 \\
\hline 7 & 0 & 1 & 0 \\
\hline 8 & 0.2 & 0.4 & 0.4 \\
\hline 9 & 0.2 & 0.2 & 0.6 \\
\hline 10 & 0 & 0.6 & 0.4 \\
\hline 11 & 0.6 & 0.4 & 0 \\
\hline 12 & 0.2 & 0.8 & 0 \\
\hline 13 & 0.4 & 0.2 & 0.4 \\
\hline 14 & 0.4 & 0.6 & 0 \\
\hline 15 & 0 & 0.2 & 0.8 \\
\hline 16 & 0.6 & 0.2 & 0.2 \\
\hline 17 & 0.4 & 0 & 0.6 \\
\hline 18 & 1 & 0 & 0 \\
\hline 19 & 0 & 0.4 & 0.6 \\
\hline 20 & 0.6 & 0 & 0.4 \\
\hline 21 & 0.8 & 0.2 & 0 \\
\hline
\end{tabular}

Table 3: Sands combinations of prepared SCC mixtures.

Table 4 indicates that the derived models have a good correlation coefficients, except for SPD $\left(R^{2}=0.52\right)$. A negative coefficient indicates that the increase in associate factor results in a reduction of the response.

Table 4 : Model parameters estimates of fresh properties responses.

\begin{tabular}{|c|c|c|c|c|c|c|}
\hline \multirow{2}{*}{$\Xi$} & \multicolumn{2}{|c|}{ SPD } & \multicolumn{2}{c|}{ T500 (s) } & \multicolumn{2}{c|}{ J-ring (cm) } \\
\cline { 2 - 7 } & \multicolumn{2}{|c|}{$\mathrm{R}^{2}=0.52$} & \multicolumn{2}{c|}{$\mathrm{R}^{2}=0.73$} & \multicolumn{2}{c|}{$\mathrm{R}^{2}=0.86$} \\
\cline { 2 - 7 } & Coeff. & $p$-value & Coeff. & $p$-value & Coeff. & $p$-value \\
\hline$b_{1}$ & 1.5 & $<0.0001$ & 4.7 & 0.0135 & 72.5 & $<0.0001$ \\
\hline$b_{2}$ & 1.5 & $<0.0001$ & 3.9 & 0.0003 & 64.4 & $<0.0001$ \\
\hline$b_{3}$ & 1.6 & $<0.0001$ & 19.1 & $<0.0001$ & 43 & 0.0539 \\
\hline$b_{4}$ & 0.37 & 0.0227 & $/$ & $/$ & $\mathrm{N}-\mathrm{S}$ & 0.3572 \\
\hline$b_{5}$ & 0.33 & 0.0403 & -25 & 0.0152 & 48.5 & 0.0067 \\
\hline$b_{6}$ & 0.4 & 0.0164 & $/$ & $/$ & $\mathrm{N}-\mathrm{S}$ & 0.2275 \\
\hline
\end{tabular}

However, it should be taken in account that the increase in a given factor, leads to a decrease in other factors, because the factors are constituent proportions of a mixture.

The derived models have been established using the method of least squares that consists minimizing the sum of squares of residuals. The predicted-to-observed plots shown in Fig. 3, indicate that the points seem to be distributed inside the confidence curves limits. 

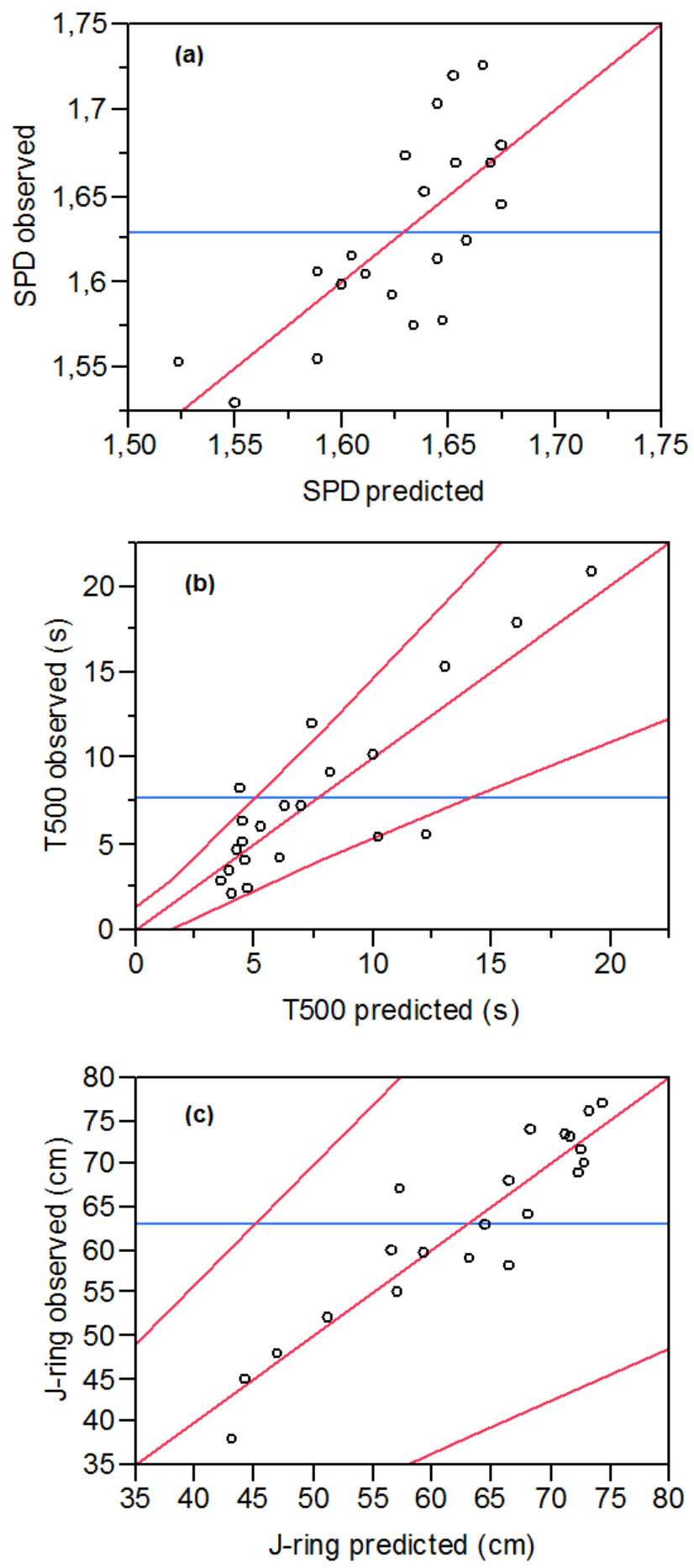

Fig 2: Observed-to-predicted plots for: (a) SPD, (b) T500 and (c) J-ring.

\subsection{Exploitation of models}

The established models can be used to present results in contour plots that illustrate the effect of RS, CS and DS proportions on sands compactness, flowability and passing ability of SCC.

Ternary contour plot presented in Fig. 3, illustrates the effect of RS, CS and DS proportions on SPD. From this figure, it can be seen that the increase of CS and DS proportions in binary systems RS-CS and RS-DS or ternary system RS-CS-DS, increased SPD until a maximum value (around 1.68) then decreased. The maximum SPD value can be reached with the follow ternary proportions (approximately: $40 \%$ of CS, $30 \%$ of DS and 30\% of RS). This can be explained by the filling effect of fine DS grains and the high filler content of CS. 


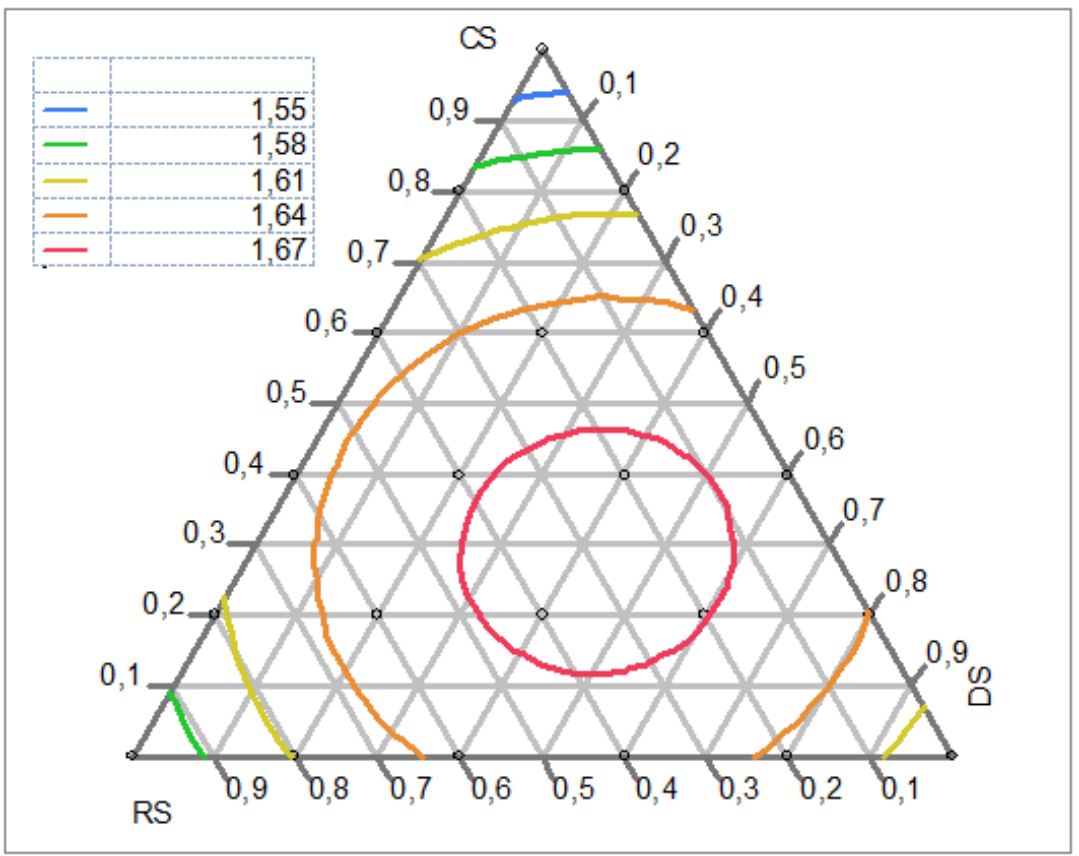

Fig 3: Ternary plot of SPD as function of RS, CS and DS proportions.

Fig. 4 illustrates the ternary contour plots of T500 flow time for SCC mixtures made of RS, CS and DS. As illustrated in Fig. 4, T500 time increased as the proportions of CS increased in RS-CS and CS-DS binary blends. This is apparently caused by the high filler content of CS. It can be also seen that T500 decreased as the proportions of DS increased in RS-DS binary system.

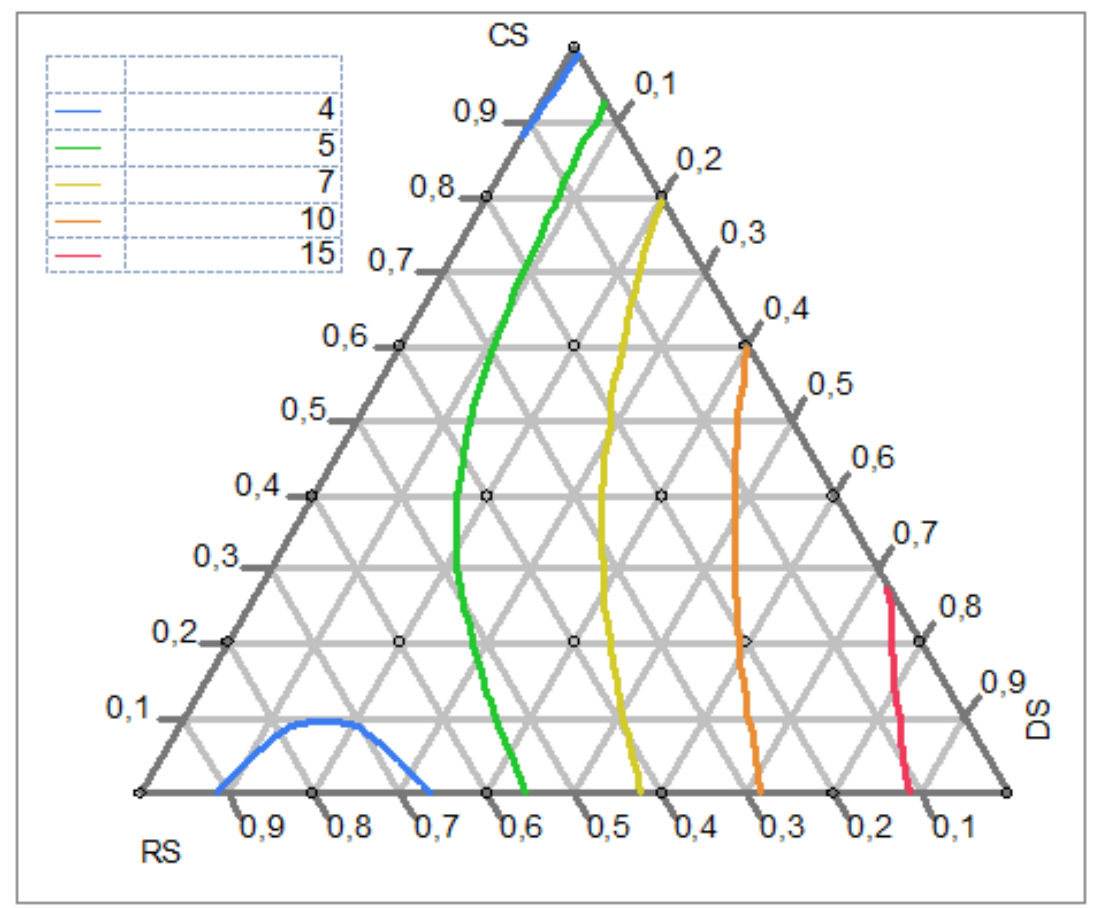

Fig 4. Ternary plot of T500 (s) as function of RS, CS and DS proportions.

The effect of different sands proportions on the J-ring slump diameter is plotted in Fig. 5. Results show that J-ring values increased for both CS and DS in RS-CS and RS-DS binary systems. 


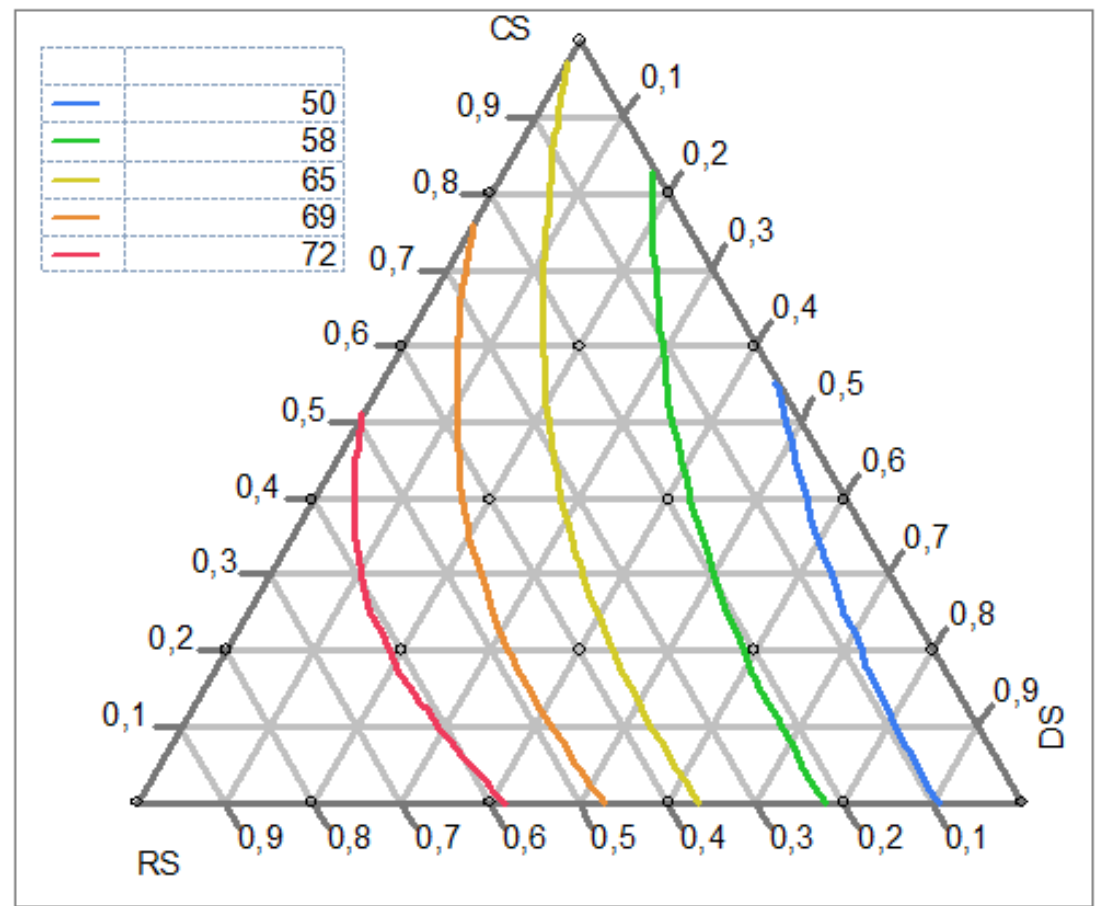

Fig 5. Ternary plot of J-ring $(\mathrm{cm})$ as function of RS, CS and DS proportions.

\section{Conclusions}

The mixture design approach developed in this experimental work is useful to evaluate the effect of three types of sand proportions (RS, CS and DS), in binary and ternary systems, on fresh properties of SCC. Using only 21 SCC mixtures, this statistical design approach provides mathematical models that can be used to present results in ternary contour plots. Such graphical representation offer a simple visual tool for optimizing RS, CS and DS proportions in binary and ternary systems, to meet different performances criteria of SCC.

Based on obtained results, the following conclusions can be drawn:

- Sand packing density (SPD) increased with the increase of CS and DS proportions in RSCS and RS-DS binary systems and RS-CS-DS ternary system. Sand mixture composed with approximately $30 \%$ of DS, $40 \%$ of CS and $30 \%$ of RS proportions, yielded SCC mixtures with high packing density.

- The passing ability, expressed by T500 flow time, increased with the increase of CS proportion in RS-DS binary mixture and decreased with the increase of DS proportion in RS-CS binary system.

- The increase in DS and CS proportions with RS as binary or ternary systems, enhanced flowability and passing ability through J-ring bars.

\section{References}

Abidelah A, Bouchair A, Kerdal D, Ayed K (2009). Characterization of a self-compacting sand concrete using the quarry waste. Canad J Civil Eng, 36: 1773-82.

AFGC, Association Française de Génie Civil (2008). Recommendations for use of self-Compacting Concrete, Scientific and technical documents, P N B@P.

Albert KHK., Ivan YTN (2010). Improving performance and robustness of SCC by adding supplementary cementitious materials, Constr Build Mater, 24: 2260-66.

Al-harthy AS, Abdel Halim M, Taha R, Al-jabri KS (2007). The properties of concrete made with fine dune sand. Constr Build Mater, 21:1803-08. 
Bayramov F, Taşdemir C, Taşdemir M A. (2004). Optimisation of steel fibre reinforced concretes by means of statistical response surface method. Cement Concrete Compos, 26:665-75.

Bédérina M, Khenfer MM, Dheilly RM, Quéneudec M (2005). Reuse of local sand: effect of limestone filler proportion on the rheological and mechanical properties of different sand concretes. Cement Concrete Res, 35:1172-79.

Benabed B, Kadri E, Azzouz L, Kenai S (2012). Properties of self-compacting mortar made with various types of sand. Cement Concrete Compos, 34:1167-73.

Bouziani T (2013). Assessment of fresh properties and compressive strength of self-compacting concrete made with different sand types by mixture design modelling approach. Constr Build Mater, 49:308-14.

Bouziani T, Bédérina M, Hadjoudja M (2012a). Effect of dune sand on the properties of flowing sand concrete (FSC). Inter J Concrete Struct Mater, 6:59-64.

Bouziani T, Benmounah A, Bédérina M (2012b). Statistical modelling for effet of mix-parameters on properties of high flowing sand concrete. J Cent South Univ, 19:2966-75.

Felekoğlu B (2008a). A comparative study on the performance of sands rich and poor in fines in selfcompacting concrete. Constr Build Mater, 22:646-54.

Felekoğlu B, Sarıkahya H (2008b). Effect of chemical structure of polycarboxylate-based superplasticizers on workability retention of self-compacting concrete, Constr Build Mater, 22:1972-80.

Girish S, Ranganath RV, Vengala J (2010). Influence of powder and paste on flow properties of SCC. Constr Build Mater, 24:2481-88.

Goupy J, Creighton L (2007). Introduction to design of experiments with JMP examples. $3^{\text {rd }}$ ed. Cary, NC: SAS Institute Inc.

Khayat KH, Ghezal A, Hadriche MS (1999). Factorial design models for proportioning self-consolidating concrete. Mater Struct, 32:679-86.

Kay EA, Frearson JPH (1994). An investigation into the use of dune sand in concrete. In: Fookes PG, Party RHG, editors. Proceeding of the 1st International Symposium on Engineering of Arid Soils. Ballkema, Rotterdam, pp.261-72.

Okamura H, Ouchi M (2003). Self-compacting concrete. J Adv Concr Technol, 1:1-15.

Ramge P, Proske T, Kühne HC (2010). Segregation of Coarse Aggregates in Self-Compacting Concrete. In: Khayat KH, Feys D, editors. Design, Production and Placement of Self-Consolidating Concrete, RILEM Bookseries 1, pp.113-25.

Sonebi M, Svermova L, Bartos PJM (2005). Statistical modeling of cement slurries for self-compacting SIFCON containing silica fume. Mat Struct, 38:79-86.

Yahia A, Khayat KH (2001). Experiment design to evaluate interaction of high-rangewater-reducer and antiwashout admixture in high-performance cement grout. Cement Concrete Res, 31:749-57.

Zhu W, Gibbs J (2005). Use of different limestone and chalk powders in self-compacting concrete. Cement Concrete Res, 35: 1457-62. 